\title{
Relationship between buccal branches of the facial nerve, parotid duct, buccal fat pad and Zuker's point
}

\author{
Özlem Elvan ${ }^{1}$ (D), Alev Bobuş Örs² (D) \\ ${ }^{1}$ Institute of Health Sciences, Mersin University, Mersin, Turkey \\ ${ }^{2}$ Department of Anatomy, School of Medicine, Mersin University, Mersin, Turkey
}

\begin{abstract}
Objectives: The aim of this study was to determine the relationship of the buccal branches of the facial nerve with the parotid duct, the buccal fat pad and the Zuker's point, and reveal the incidence of the neural communications of buccal branch with the zygomatic and marginal mandibular branches of the facial nerve.

Methods: Fifteen formalin-fixed cadaveric heads (8 females and 7 males) with a mean age of $73.93 \pm 14.42$ years were dissected bilaterally to reveal the buccal, zygomatic and marginal mandibular branches of the facial nerve, the parotid duct and the buccal fat pad. Positional relationships of these structures and the anatomical features of buccal and zygomatic branches were evaluated.

Results: The mean number of buccal and zygomatic branches was $2.40 \pm 0.62$ and $1.90 \pm 0.60$ respectively. Buccal branches crossed the parotid duct in $67 \%$, formed a plexus along the parotid duct in $27 \%$ and coursed superior or inferior to the parotid duct without crossing in $6 \%$ of the dissected specimens. The mean number of intersection points of buccal branches on parotid duct was $4.03 \pm 1.03$. Parotid duct crossed along the superior border of buccal fat pad in $66 \%$, deep to buccal fat pad in $27 \%$ and between the superior and inferior lobes of buccal fat pad in 7\%. Buccal branches crossed superficial to buccal fat pad in $80 \%$ and some branches passed superficial and through the buccal fat pad in $20 \%$.
\end{abstract}

Conclusion: It is essential to know the positional interrelations of the buccal branches of the facial nerve with the parotid duct and buccal fat pad for clinical implications. The relation of Zuker's point with zygomatic and buccal branches and with parotid duct should not be overlooked.

Keywords: buccal branch; buccal fat pad; parotid duct; Zuker's point; zygomatic branch

Anatomy 2020;14(2):91-96 @2020 Turkish Society of Anatomy and Clinical Anatomy (TSACA)

\section{Introduction}

Buccal branches of the facial nerve (BB) run horizontally across cheek and buccal area. The BB have superficial and deep twigs. Superficial twigs of the BB run deep to subcutaneous fat and superficial musculo-aponeurotic system. Deep twigs of the BB innervate the zygomaticus major and minor, levator labii superioris, levator anguli oris, levator labii superioris alaeque nasi, small nasal muscles, buccinator and orbicularis oris muscles. ${ }^{[1-4]}$

Zygomatic branches of the facial nerve (ZB) cross the zygomatic bone towards lateral canthus and innervate orbicularis oculi muscle. These branches may also con- tribute innervation of the muscles which are innervated by the $\mathrm{BB} .^{[4]}$ The Zuker's point is defined as a clinical landmark at the vicinity of the $\mathrm{BB}$ and $\mathrm{ZB}$ that innervates the zygomaticus major muscle. It refers to the midpoint on a line drawn from crus of helix to the labial commissure. The $\mathrm{BB}$ and $\mathrm{ZB}$ have been found to lie at approximately $2.3 \mathrm{~mm}$ away from the Zuker's point. ${ }^{[5]}$

Parotid duct (PD) appears at the anterior border of the upper part of the parotid gland and passes horizontally across masseter muscle at approximately midway between the angle of the mouth and the zygomatic arch. Then it turns medially at the anterior border of masseter piercing the buccal fat pad (BFP) and buccinator muscle then opens 
into oral cavity upon a small papilla opposite the second upper molar tooth. ${ }^{[4]}$

The BFP is an encapsulated and round shaped adipose tissue which can be divided into three lobes anatomically as anterior, intermediate and posterior. ${ }^{[6-8]}$ The anterior lobe is triangular and located below zygomatic arch. The intermediate lobe lies between the anterior and posterior lobes. The posterior lobe is located in masticatory space forming buccal, pterygoid, pterygopalatine, and temporal extensions. ${ }^{[7]}$ It functions to fill deep tissue spaces and act as gliding pads during contraction of masticatory and mimic muscles. ${ }^{[6]}$

The $\mathrm{BB}$, the $\mathrm{PD}$ and the $\mathrm{BFP}$ are interrelated structures of the face. They could be damaged in operations such as rhytidectomy, ${ }^{[5,9]}$ parotid surgeries ${ }^{[9-13]}$ and BFP surgeries $^{[7,1,1,15]}$ since they run close to each other. Injury to the $\mathrm{BB}$ or $\mathrm{ZB}$ may result in loss of function of the muscles involved. Damage to the parotid system can result in a PD fistula or a sialocele. ${ }^{[12]}$ Blind dissection of the BFP may cause injury to the $\mathrm{BB}$ and $\mathrm{PD}$, hematoma formation by bleeding ${ }^{[16]}$ and iatrogenic rupturing of the PD ${ }^{[17]}$ While discrepancy exists regarding the positional relationships of the $\mathrm{BB}, \mathrm{PD}$ and $\mathrm{BFP}$ in the literature, there is need to redefine these interrelations. Therefore, goals of this study were to define the relationship of $\mathrm{BB}$ with the $\mathrm{PD}$, the $\mathrm{BFP}$ and the Zuker's point, and to determine the incidence of the the neural communications of $\mathrm{BB}$ with the $\mathrm{ZB}$ and marginal mandibular branches of the facial nerve (MMB).

\section{Materials and Methods}

Fifteen formalin-fixed cadaveric heads ( 8 females and 7 males) with a mean age of $73.93 \pm 14.42$ (range: 44-92) years were evaluated bilaterally at the Anatomy Laboratory of Mersin University after taking the approval from Clinical Research Ethics Committee of Mersin University (2018/289). Skin, subcutaneous tissue and superficial musculo-aponeurotic system were dissected after preauricular incision. Branches of the facial nerve especially the $\mathrm{BB}, \mathrm{ZB}$ and $\mathrm{MMB}, \mathrm{PD}$ and $\mathrm{BFP}$ were revealed. The $\mathrm{BB}, \mathrm{ZB}$ and $\mathrm{MMB}$ were dissected from their exit through the parotid gland until their entrance point into the facial muscles. The PD was dissected from its exit point at the anterior border of the parotid gland until its entrance to the oral cavity through the buccinator muscle. Any facial nerve branch lying superficial to or in contact with the zygomatic arch was accepted as the ZB. Whereas, any branch lying inferior to the zygomatic arch was accepted as the $\mathrm{BB}$, as stated by Kehrer et al. ${ }^{[18]}$ Dissections were carried under a surgical microscope (Zeiss OPMI Pico, Jena, Germany) and a digital caliper ( $0.01 \mathrm{~mm}$ precision) was used for measurements. Dissections and meas- urements were conducted by the same researcher (ÖE). The following parameteres were evaluated and recorded:

- Number of the BB anterior to the parotid gland (proximally) and around the BFP (distally).

- The origin of BB.

- The relationships of the $\mathrm{BB}$ with the $\mathrm{ZB}$ and the $\mathrm{MMB}$.

- The number of the ZB.

- The Zuker's point was determined as mid-distance between commissura labiorum and crus of helix ${ }^{[5]}$ the structures on/around it were defined accordingly.

- Positional relationship of the BB with the PD (cross type: One or more than one branch crossed the PD; plexus type: Branches formed plexus on the PD; no crossing type: Branches coursed superior or inferior to the PD without crossing it).

- Positional relationships of the PD with the BFP (the PD crossed along superior border of the BFP; the PD crossed deep to the BFP; the PD crossing superficial to the BFP). ${ }^{[16]}$

- Positional relationship of the $\mathrm{BB}$ with the BFP (branches crossed superficial to the BFP; some twigs passed through/within the BFP). ${ }^{[16]}$

\section{Results}

The mean number of the $\mathrm{BB}$ proximal to the $\mathrm{PD}$ was $2.40 \pm 0.62$ (range: $1-4$ ) branches and distal to the PD was $4.03 \pm 1.03$ (range: $2-6$ ) branches. The number of proximal and distal branches was symmetric in $2 / 15$ specimens (13\%).

The BB originated from both temporofacial and cervicofacial common trunks in $27 / 30$ sides (90\%), only from temporofacial trunk in $2 / 30(7 \%)$ sides and only from cervicofacial trunk in one side (3\%). The $\mathrm{BB}$ originated from both temporofacial and cervicofacial common trunks were symmetric in $4 / 15$ specimens (27\%).

The relationships of the $\mathrm{BB}$ with the $\mathrm{ZB}$ and the $\mathrm{MMB}$ are shown in Table 1. They were grouped as "no relation", "communicating", "common trunk" and "communicating+common trunk" regarding sides. The communication between the $\mathrm{BB}$ and $\mathrm{ZB}$ was symmetric in one case

Table 1

The relationships of the $\mathrm{BB}$ with the $\mathrm{ZB}$ and $\mathrm{MMB}$ regarding number of sides.

\begin{tabular}{lcccc} 
& $\begin{array}{c}\text { No } \\
\text { relation }\end{array}$ & Communication & $\begin{array}{c}\text { Common } \\
\text { trunk }\end{array}$ & $\begin{array}{c}\text { Communication+ } \\
\text { Common trunk }\end{array}$ \\
\hline BB-ZB & 7 & 7 & 5 & 11 \\
\hline BB-MMB & 19 & 3 & 7 & 1 \\
\hline
\end{tabular}

BB: buccal branches of the facial nerve; MMB: marginal mandibular branches of the facial nerve; ZB: zygomatic branches of the facial nerve. 
(6\%) and with MMB, in 5 cases (33\%). Neural communications and formation of common trunk between the $\mathrm{BB}$ and $\mathrm{ZB}$ was present in $2 / 15$ specimens (13\%).

The mean numbers of the $\mathrm{ZB}$ were $1.90 \pm 0.60$ (range: 1-3) branches. The numbers of $Z B$ were symmetrical in $8 / 15$ specimens $(53 \%)$.

The Zuker's point was determined $58.21 \pm 4.24 \mathrm{~mm}$ away from the crus of helix (range: 50.00-65.00) $\mathrm{mm}$. The Zuker's point crossedmet doğru terim mi tam anlayamadım by a nerve branch in 9 specimens $(6 \mathrm{ZB}, 2 \mathrm{BB}$ and 1 buccozygomatic trunk). There were $13 \mathrm{ZB}, 4 \mathrm{BB}$ and 4 buccozygomatic trunks running superior and in close proximity to Zucker's point and 9 PD, 6 BB, 1 ZB and 1 buccozygomatic trunk running inferior to Zucker's point.

When the positional relationships of the $\mathrm{BB}$ with the PD were evaluated; crossing type found in 20/30 (67\%), plexus type in $8 / 30(27 \%)$ and no crossing type in $2 / 30$
(6\%) sides where the BB coursed superior or inferior to the PD without crossing it (Figures 1a-c). The positional relationships of the $\mathrm{BB}$ and $\mathrm{PD}$ were symmetric in $8 / 15$ cases $(53 \%)$ as it was of plexus type in one case and crossing type in other acses. The mean number of intersection points of the $\mathrm{BB}$ and the $\mathrm{PD}$ was $4.03 \pm 1.03$ (range: $2-6$ ) points.

The PD crossed along the superior border of the BFP in 20/30 (66\%) (Figures 1a and b); deep to the BFP in $8 / 30(27 \%)$ and between superior and inferior lobes of the BFP in 2/30 (7\%) of sides (Figures $\mathbf{d}-\mathbf{f}$ ). The positional relationships of the PD and BFP were symmetric in $8 / 15$ specimens (53\%). In 7 of those cases, the PD crossed along the superior border of the BFP and in one case the PD crossed deep to the BFP.

When positional relationships of the $\mathrm{BB}$ with the $\mathrm{BFP}$ examined, it was observed that the $\mathrm{BB}$ crossed superficial
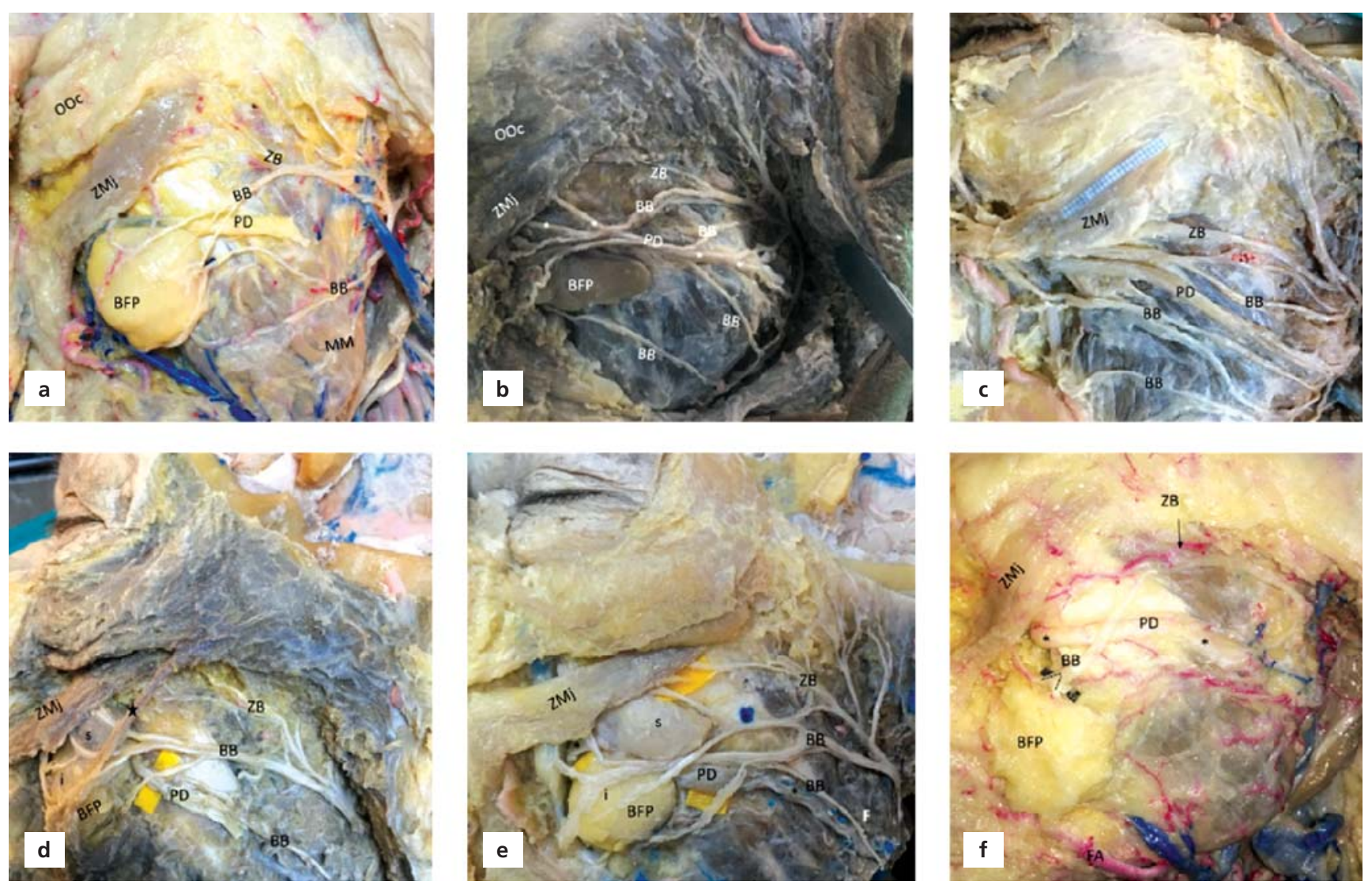

Figure 1. Relationships between the BB, BFP, FA, MM and PD on left sided specimens. (a) The BB crossed the PD. The BB were superficial to the BFP. The PD ran superior border of the BFP. (b) The BB formed a plexus on the PD. The PD was superior to the BFP. (c) The BB coursed superior and inferior to the PD without crossing it. (d) The PD ran deep to the BFP. (e) The PD coursed between superior and inferior lobes of the BFP. The blue spot indicated the Zuker's point just superior to the buccozygomatic trunk. (f) The BB coursed through and deep to the BFP. BB: Buccal branch of the facial nerve; BFP: buccal fat pad; FA: facial artery; i: inferior lobe of buccal fat pad; marks: PDs' continuation; MM: marginal mandibular branch of the facial nerve; OOc: orbicularis oculi muscle; PD: parotid duct; s: superior lobe of buccal fat pad; star: zygomaticus minor muscle; ZB: zygomatic branch of the facial nerve; ZMj: zygomaticus major muscle. 
to the BFP in 24/30 (80\%) and some twigs of BB passed superficial and some twigs passed deep/through the BFP in $6 / 30(20 \%)$ of sides (Figures 1a and f).

\section{Discussion}

There is a large diversity regarding the number of $\mathrm{BB}$ which has been reported to be composed of 1 to 5 branches. ${ }^{[1,3,4,16,19-21]}$ Only a single BB has been reported to be found $2.5 \%$ to $85 \%$, two branches $15 \%$ to $50 \%$, three branches $48.6 \%$ and four branches $5.7 \% \cdot{ }^{[1,22-24]}$ In the present study, the mean number of $\mathrm{BB}$ was identified as $2.40 \pm 0.62$ (range: 1-4) branches proximally and $4.03 \pm 1.03$ (range: 2-6) branches distally. It is important to note that main $\mathrm{BB}$ observed to divide into terminal branches around the BFP running to the relevant muscles. However, Saylam et al. ${ }^{[23]}$ have reported that $55 \%$ of the $\mathrm{BB}$ divided into two branches, $18 \%$ divided into three branches and the $27 \%$ had a plexiform pattern.

The BB is classically defined to be formed by two roots, one from the temporofacial and one from the cervicofacial division, or from a common stem with the $\mathrm{MMB}$ or the $\mathrm{ZB} \cdot{ }^{[19,25,26]}$ In the present study, the $\mathrm{BB}$ originated from both temporofacial and cervicofacial trunks in $90 \%$, only from temporofacial trunk in $7 \%$ and only from cervicofacial trunk in $3 \%$ of sides. The findings of Kwak et al. ${ }^{[27]}$ were similar to the present study that in $93.2 \%$ of cases BB originated from two trunks; one from the temporofacial and one from the cervicofacial division. In $6.8 \%$ of cases the $\mathrm{BB}$ originated from either temporofacial or cervicofacial trunks.

Interconnections between the $\mathrm{BB}$ and the $\mathrm{ZB}$ or connections of $\mathrm{BB}$ with the MMB have been reported previously ${ }^{[19,27,28]}$ Kwak et al ${ }^{[27]}$ categorized facial nerve branching pattern according to origin of the BB. They reported that there were communicating branches between the $\mathrm{BB}$ and the $\mathrm{ZB}$ with a prevelance of $70 \%$ and between the $\mathrm{BB}$ and the $M M B$ with a prevelance of $42 \%$. Consistent decussations between the $\mathrm{BB}$ and the $\mathrm{ZB}$ were noted as $67 \%$ in classification of Davis et al. ${ }^{[28]}$ Katz and Catalano ${ }^{[25]}$ reported that the MMB may communicate with the BB in $10 \%$ of cases. The present study revealed that there was no crossing of the $\mathrm{BB}$ with the $\mathrm{ZB}$ in $23 \%$. Our results showed but there were neural communications between $\mathrm{BB}$ and $\mathrm{ZB}$ in $23 \%$ and in $17 \% \mathrm{BB}$ and $\mathrm{ZB}$ formed a common trunk. Interestingly, there were both neural communications and common trunk formation in $37 \%$ of the dissected specimens. The relationship of the $\mathrm{BB}$ with the MMB showed no relation in $63 \%$, only communication in $10 \%$, a common trunk in $23 \%$ and, both communication and common trunk in $3 \%$. These findings revealed that the $\mathrm{BB}$ has more interactions with the $\mathrm{ZB}$ than the $\mathrm{MMB}$. The spontaneous recovery of motor functions and nerve relays in case of surgical lesions can be explained by these communications. ${ }^{[2,30]}$

The ZB has been generally reported to be multiple. ${ }^{[4,31]}$ In the present study, the number mean of $Z B$ was $1.90 \pm 0.60$ (range: $1-3$ ) branches. The Zuker's point was determined as $58.21 \pm 4.24 \mathrm{~mm}$ from the crus of helix (range: 50-65) mm. The intersection of the Zuker's point with the nerve branches was observed in $30 \%$ of sides. This intersection was seen in 6 out of 9 the ZB branches, 2 out of 9 the $\mathrm{BB}$ and in one side it was a buccozygomatic trunk. Not on the Zuker's point, but superior to it, there were $13 \mathrm{ZB}, 4 \mathrm{BB}$ and 4 buccozygomatic trunks. At the same time, there were $4 \mathrm{BB}$ and $\mathrm{PD}$ together, $9 \mathrm{PD}, 6 \mathrm{BB}$, one $\mathrm{ZB}$ and one buccozygomatic trunk coursing inferiorly and in close proximity to the Zuker's point. In the study of Dorafshar et al., ${ }^{[5]}$ the intersection of the branch supplying the zygomaticus major muscle and the Zuker's point has been described in $39 \%$. The branches inferior to Zuker's point were reported in $28 \%$ and superior to Zuker's point in $33 \%$. The Zuker's point has been described to be 53.33 $\mathrm{mm}$ away from the crus of helix (range: $45-63$ ) $\mathrm{mm}$. The results of that study were similar to the present study, but they did not mention about the PD. In the present study, it is also revealed that the PD was in close proximity with Zuker's point. This point is suggested as a clinical guide to help to prevent nerve injuries. ${ }^{[5]}$ The location of PD which can be found in close proximity being inferior to the Zucker's point should not be overlooked.

The BB is classicaly described that it has close relationship with the PD. The BB lies below the PD about $2.5 \mathrm{~cm}$ after emerging from the parotid gland. The PD may be crossed by communicating branches between the $\mathrm{BB}$ and $\mathrm{ZB} .{ }^{[4]}$ Pogrel et al. ${ }^{[2]}$ reported that $\mathrm{BB}$ courses below the PD in $75 \%$; above the PD in $10 \%$; two BB, one passing superior to the $\mathrm{PD}$ and one passing below it in $15 \%$. Saylam et al. ${ }^{[23]}$ reported a single BB coursing below the PD in $60 \%$ cases. Liu et al. ${ }^{[20]}$ stated that the $\mathrm{BB}$ courses within the region of $10.7 \mathrm{~mm}$ superior and 9.3 $\mathrm{mm}$ inferior to the PD. In the present study, positional relationships of $\mathrm{BB}$ with $\mathrm{PD}$ were determined in three different patterns. Majority of the BB crossed the PD $(67 \%)$, some of the branches were observed to form a plexus along the PD (27\%) and in some specimens BB were observed to course superior or inferior to PD without crossing it $(6 \%)$. The pattern that $\mathrm{BB}$, forming a plexus on the $\mathrm{PD}$, is first revealed in the present study as far as we know. Therefore, the BB forming a plexus on the PD in $27 \%$ of sides is the remarkable difference of the 
present study. In PD surgeries, these plexuses may pose a serious risk for iatrogenic injuries. These kind of cases may be more prone to injury as they are more superficial in regional surgeries.

The mean number of intersections of the $\mathrm{BB}$ and the PD has been reported as $2.49 \pm 1.15$ in the study of Tsai et al. ${ }^{[1]}$ They observed two intersection points in $37 \%$, three intersection points in $23 \%$, one intersection point in $20 \%$, four intersection points in $14 \%$ and five intersection points in $6 \%$ of cases. On the other hand, Erbil et al. ${ }^{[21]}$ reported that $\mathrm{BB}$ never crossed $\mathrm{PD}$, all were inferior to PD. In the present study, the mean number of intersection points of the $\mathrm{BB}$ and the $\mathrm{PD}$ was $4.03 \pm 1.03$ (range: $2-6$ ) and that was $67 \%$ of the sides. Additionally, BB was crossing PD in $6 \%$ of our specimens.

Gross anatomy, functions, pathology and clinical uses of the BFP has been well described in the study of Yousuf et al. ${ }^{[32]}$ However, its relationship with the $\mathrm{PD}$ and the $\mathrm{BB}$ was not mentioned. On the other hand, in the study of Hwang et al., ${ }^{[16]}$ the interrelations of BFP with $\mathrm{BB}$ and PD have been evaluated. It has been mentioned that PD crossed superficial to the buccal extension of BFP in $42.1 \%$; deep to it in $26.3 \%$; and crossed along its superior border in $31.6 \%$. In the present study, the PD was deep to the $\mathrm{BFP}$ in $27 \%$ of specimens as in previous studies. We observed that the PD crossed the superior border of the $\mathrm{BFP}$ in $66 \%$ of specimens; and run between the superior and inferior lobes of the BFP in 7\%. On the other hand, Surek et al ${ }^{[7]}$ reported that PD coursed on the superior aspect of BFP constantly. Hwang et al. ${ }^{[16]}$ also reported that $\mathrm{BB}$ crossed superficial to BFP in $73.7 \%$ and two twigs of $\mathrm{BB}$ passed through the buccal extension of BFP in $26.3 \%$. These results were in similar with our findings that the BB crossed superficial to the BFP in $80 \%$ of our specimens while some twigs passing superficial and some twigs passed through the BFP in $20 \%$. In an other study, it is mentioned that the anterior surface of $\mathrm{BFP}$ was covered by $\mathrm{BB}$ in $75 \%$, while the lateral border of $\mathrm{BFP}$ was covered by $\mathrm{ZB}$ in $90 \% .{ }^{[8]}$ But we did not detect any ZB related with the BFP. It is interesting to note that positional relationships of $\mathrm{PD}$ with the $\mathrm{BB}$ and $\mathrm{BFP}$ were symmetric in $53 \%$ of specimens.

\section{Conclusion}

This study presented the relationships of the BB ZB, PD and BFP. It is shown that position of the $\mathrm{BB}$ according to the $\mathrm{PD}$ and the BFP is not constant. While majority of the BB $(67 \%)$ crossed the PD, remarkable ratio $(27 \%)$ of $\mathrm{BB}$ formed plexus on the PD. The position of PD according to the $\mathrm{BFP}$ also varies. It is important to know that $27 \%$ of the PD run deep to $\mathrm{BFP}$ and $7 \%$ of it run between superior and inferior lobes of the BFP. Additionally, the BB course superficial to the BFP in $80 \%$, while they course both superficial and through/within the BFP in $20 \%$. Descriptive findings of this study may be helpful in several surgical, particularly reconstructive and aesthetic procedures which will be performed in this region.

\section{Conflict of Interest}

Authors declared no conflict of interest.

\section{Author Contributions}

ÖE: Project development, data collection and analysis, manuscript writing, editing; ABÖ: Project development, data analysis, editing.

\section{Ethics Approval}

This study was approved by Clinical Research Ethics Committee of Mersin University (2018/289).

\section{Acknowledgements}

We would like to thank the body donors and their families.

\section{References}

1. Mitsukawa N, Moriyama H, Shiozawa K, Satoh K. Study on distribution of terminal branches of the facial nerve in mimetic muscles. Ann Plast Surg 2014;72:71-4.

2. Hwang K. Surgical anatomy of the facial nerve relating to facial rejuvenation surgery. J Craniofac Surg 2014;25:1476-81.

3. Bendella H, Spacca B, Rink S, Stoffels HJ, Nakamura M, Scaal M, Angelov DN. Anastomotic patterns of the facial parotid plexus (PP): a human cadaver study. Ann Anat 2017;213:52-61.

4. Standring S, Borley NR, Collins P, Crossman AR, Gatzoulis MA, Healy JC (Editors). Gray's anatomy: the anatomical basis of clinical practice. 40th ed. London: Churchill Livingstone Elsevier; 2008.

5. Dorafshar AH, Borsuk DE, Bojovic B, Brown EN, Manktelow RT, Zuker RM, Rodriguez ED, Redett RJ. Surface anatomy of the middle division of the facial nerve: Zuker's point. Plast Reconstr Surg 2013;131:253-7.

6. Zhang HM, Yan YP, Qi KM, Wang JQ, Liu ZF. Anatomical structure of the buccal fat pad and its clinical adaptations. Plast Reconstr Surg 2002;109:2509-18.

7. Surek CC, Kochuba AL, Said SA, Cho KH, Swanson M, Duraes E, McBride J, Drake RL, Zins JE. External approach to buccal fat excision in facelift: anatomy and technique. Aesthet Surg J 2020 Jan 22; sjaa015. doi:10.1093/asj/sjaa015

8. Loukas M, Kapos T, Louis RG Jr, Wartman C, Jones A, Hallner B. Gross anatomical, CT and MRI analyses of the buccal fat pad with special emphasis on volumetric variations. Surg Radiol Anat 2006;28: 254-60.

9. Lee JY, Kim JN, Yoo JY, Shin KJ, Song WC, Koh KS, Kim SH, Choi HG. Topographic relationships between the transverse facial 
artery, branches of the facial nerve, and the parotid duct in the lateral midface in a Korean population. Ann Plast Surg 2014;73:321-4.

10. Steinberg MJ, Herréra AF. Management of parotid duct injuries. Oral Surg Oral Med Oral Pathol Oral Radiol Endod 2005;99:136141.

11. Tsai CH, Ting CC, Wu SY, Chiu JY, Chen H, Igawa K, Lan TH, Chen CM, Takato T, Hoshi K, Ko EC. Clinical significance of buccal branches of the facial nerve and their relationship with the emergence of Stensen's duct: an anatomical study on adult Taiwanese cadavers. J Craniomaxillofac Surg 2019;47:1809-18.

12. Richards AT, Digges N, Norton NS, Quinn TH, Say P, Galer C, Lydiatt K. Surgical anatomy of the parotid duct with emphasis on the major tributaries forming the duct and the relationship of the facial nerve to the duct. Clin Anat 2004;17:463-7.

13. Mahmmood VH. Buccal branch as a guide for superficial parotidectomy. J Craniofac Surg 2012;23:e447-9.

14. Stuzin JM, Wagstrom L, Kawamoto HK, Baker TJ, Wolfe SA. The anatomy and clinical applications of the buccal fat pad. Plast Reconstr Surg 1990;85:29-37.

15. Chaudhary B, Gong Z, Lin Z, Abbas K, Ling B, Liu H. Reconstruction of intraoral maxillary defect with buccal fat pad. J Craniofac Surg 2014;25:2174-7.

16. Hwang K, Cho HJ, Battuvshin D, Chung IH, Hwang SH. Interrelated buccal fat pad with facial buccal branches and parotid duct. J Craniofac Surg 2005;16:658-660.

17. Vieira GM, Jorge FD, Franco EJ, Dias LDC, Guimarães MDCM, Oliveira LA. Lesions of the parotid gland and buccal artery after buccal fat pad reduction. J Carniofac Surg 2019;30:790-2.

18. Kehrer A, Engelmann S, Bauer R, Taeger C, Grechenig S, Kehrer M, Prantl L, Tamm ER, Bleys RLAW, Mandlik V. The nerve supply of zygomaticus major: variability and distinguishing zygomatic from buccal facial nerve branches. Clin Anat 2018;31:560-5.

19. Shoja MM, Tubbs RS, Loukas M. Bergman's comprehensive encyclopedia of human anatomic variation. Hoboken (NJ): John Wiley \& Sons 2016.

20. Liu AT, Jiang H, Zhao YZ, Yu DZ, Dang RS, Zhang YF, Zhang JL. Anatomy of buccal and marginal mandibular branches of facial nerve and its clinical significance. Zhonghua Zheng Xing Wai Ke Za Zhi 2007;23:434-7.
21. Erbil KM, Uz A, Hayran M, Mas N, Senan S, Tuncel M. The relationship of the parotid duct to the buccal and zygomatic branches of the facial nerve; an anatomical study with parameters of clinical interest. Folia Morphol (Warsz) 2007;66:109-14.

22. Tansatit T, Phanchart $\mathrm{P}$, Chinnawong D, Apinuntrum $\mathrm{P}$, Phetudom T, Sahraoui YM. A cadaveric study ofthe communication patterns between the buccal trunks of the facial nere and the infraorbital nerve in the midface. J Craniofac Surg 2016;27:214-18.

23. Saylam C, Ucerler H, Orhan M, Ozek C. Anatomic landmarks of the buccal branches of the facial nerve. Surg Radiol Anat 2006;28:462-7.

24. Pogrel MA, Schmidt B, Ammar A. The relationship of the buccal branch of the facial nerve to the parotid duct. J Oral Maxillofac Surg 1996;54:71-3.

25. Katz AD, Catalano P. The clinical significance of the various anastomotic branches of the facial nerve. Report of 100 patients. Arch Otolaryngol Head Neck Surg 1987;113:959-62.

26. Namking $M$, Boonruangsri P, Woraputtaporn W, Güldner FH. Communication between the facial and auriculotemporal nerves. J Anat 1994;185:421-6.

27. Kwak HH, Park HD, Youn KH, Hu KS, Koh KS, Han SH, Kim HJ. Branching patterns of the facial nerve and its communication with the auriculotemporal nerve. Surg Radiol Anat 2004;26:494500.

28. Davis RA, Anson BJ, Budlinger JM, Kurth LR. Surgical anatomy of the facial nerve and parotid gland as based upon a study of 350 cervicofacial halves. Surg Gynecol Obstet 1956;102:385-412.

29. Laurentjoye M, Veyret A, Ella B, Uzel AP, Majoufre-Lefebvre C, Caix P, Ricard AS. Surgical anatomy of the preauricular anteroparotid approach for mandibular condyle surgery. Surg Radiol Anat 2014;36:883-8.

30. Roostaeian J, Rohrich RJ, Stuzin JM. Anatomical considerations to prevent facial nerve injury. Plast Reconstr Surg 2015;135:1318-27.

31. Saylam C, Ucerler H, Orhan M, Ozek C. Anatomic guides to precisely localize the zygomatic branches of the facial nerve. J Craniofac Surg 2006;17:50-3.

32. Yousuf S, Tubbs RS, Wartmann CT, Kapos T, Cohen-Gadol AA, Loukas M. A review of the gross anatomy, functions, pathology, and clinical uses of the buccal fat pad. Surg Radiol Anat 2010;32: $427-36$.

Correspondence to: Özlem Elvan, PhD

Institute of Health Sciences, Mersin University,

Çiftlikköy Campus, Yenişehir, 33343, Mersin, Turkey

Phone: +90 5327274186

e-mail: ozlemelvan33@gmail.com

Conflict of interest statement: No conflicts declared.

This is an open access article distributed under the terms of the Creative Commons Attribution-NonCommercial-NoDerivs 4.0 Unported (CC BY-NCND4.0) Licence (http://creativecommons.org/licenses/by-nc-nd/4.0/) which permits unrestricted noncommercial use, distribution, and reproduction in any medium, provided the original work is properly cited. How to cite this article: Elvan Ö, Bobuş Örs A. Relationship between buccal branches of the facial nerve, parotid duct, buccal fat pad and Zuker's point. Anatomy 2020;14(2):91-96. 